\title{
Aerobic Exercise with Superimposed Virtual Reality Improves Cognitive Flexibility and Selective Attention in Young Males
}

\author{
Borja Sañudo ${ }^{1}$, Ellie Abdi ${ }^{2}$, Mario Bernardo-Filho ${ }^{3}$ (i) and Redha Taiar ${ }^{4, *(\mathbb{D}}$ \\ 1 Departamento de Educación Física y Deporte, Universidad de Sevilla, 41013 Sevilla, Spain; bsancor@us.es \\ 2 Center of Pedagogy, Montclair State University, Upper Montclair, NJ 07043, USA; ellieabdi@verizon.net \\ 3 Departamento de Biofísica e Biometria, Universidade do Estado do Rio de Janeiro, \\ 22050-032 Rio de Janeiro, Brazil; bernardofilhom@gmail.com \\ 4 Département d'Education Physique et sportive (EPS), Université de Reims, 51687 Reims, France \\ * Correspondence: redha.taiar@univ-reims.fr; Tel.: +33-326918467
}

Received: 1 October 2020; Accepted: 11 November 2020; Published: 12 November 2020

\begin{abstract}
The literature to date is limited regarding the implantation of VR in healthy young individuals with a focus on cognitive function. Thirty healthy males aged between 22.8 and 24.3 years volunteered to participate in the study randomly and were assigned to one of two groups with alike exercises: an experimental group (GE, $n=15)$ that performed an exercise protocol with a VR game and a controlled group that performed the exercise protocol without the VR (CON, $n=15)$. A 128-card computerized version of the Wisconsin Card Sorting Task (WCST) and the Stroop test were completed before and after the exercise protocol. There was a significant interaction effect between time and condition for WCST preservation errors $\left(\mathrm{F}_{1,30}=4.59, p=0.041, \eta^{2} \mathrm{p}=0.141\right)$ and a significant time effect for all WCST and Stroop outcomes in GE. Results of preliminary findings suggest that the use of a VR platform offers effective benefits with respect to cognitive flexibility and selective attention. In addition, participants can achieve additional benefits in cognitive flexibility by engaging in a traditional exercise protocol of a similar volume.
\end{abstract}

Keywords: virtual reality; physical exercise; benefits; cognitive flexibility; attention; young males

\section{Introduction}

Physical exercise is considered one of the main strategies to improve physical functioning at all ages [1]. In fact, the health benefits of exercising to improve the ability to carry out everyday activities [2-4] as well to manage numerous clinical conditions $[5,6]$ have been well documented.

Exercise has been shown to improve physical functioning; nevertheless, the effects of exercise may vary with the degree of frailty, the format and intensity of the exercise intervention, and the level of supervision [7].

eHealth interventions are becoming increasingly used in public health, with virtual reality (VR) being one of the most exciting recent developments [8], with applications from flight simulators to biomedical uses [9]. Unlike traditional methods, VR places the users inside an experience, whereby, instead of viewing a screen, users are immersed and able to interact with three-dimensional (3D) worlds within a controlled setting to create a simulated environment [10,11]. In addition, VR allows its users to increase the benefits of exercising in comparison to traditional practice [11,12]. In a previous study [13], participants rated the Astrojumper video game extremely positively and experienced a significant increase in heart rate after gameplay. Additionally, VR-enhanced exercises are on the rise in the marketplace and in academic research $[14,15]$. 
The body of research is replete with evidence of VR's effects on exercise in clinical mental health cases [16-19] and physical medical cases [20-24] or both [25,26]. However, in these cases, a wide variety of forms of VR exercises are explored for the potential to increase physical activity. Together with the aforementioned benefits, these technologies were also suggested to influence cognitive function in different population groups $[27,28]$, with significant effects on cognitive interference (i.e., Stroop test) [28] and flexibility (i.e., Wisconsin Card Sorting Task-WCST) [29]. These changes in cognitive function after VR exposure have been associated with different mechanisms, including behavioral and physiological responses [30]. Despite some discrepancy between studies, video games were found to have beneficial effects, positively associated with cognitive functions [31]. VR video games were also found to enhance cognitive functions better than conventional methods of learning [32].

Many studies have demonstrated that the sensory and motor systems are activated during conceptual physiological processing [33]. Such results have been interpreted as indicating that concepts and important aspects of cognition, more broadly, are embodied [34]. In support of this, there is a physiological link between the body and mind, with routine exercise generating physiological adaptations to the body and brain, where it enhances both physical health and cognitive function [35]. In a previous study, an intervention was specifically tailored to include both physical and cognitive demands, where a designed sport group showed the largest gains in all cognitive measures [33]. Therefore, approaches within an embodied cognition framework provide evidence that the capacity to understand an individual's cognitive function while exercising is a prime area where this embodiment is manifested.

Embodied cognition is a concept that frequently arises in discussions of VR [36]. However, the implementation of VR in healthy young individuals is not well documented in the literature, although few researchers have reported motivational and affective impacts [37-39]. A previous study [40] indicated that VR improves performance and the affective response to aerobic exercise after testing 60 female participants aged 18-30 years. Likewise, O'Donovan and Hussey [41] examined twenty-eight healthy participants (18 male, aged 19 to 27 years) playing either Wii Sports Boxing, Tennis and Baseball, or Wii Sports Boxing and Wii Fit Free Jogging. The results determined that the experience of gaming may affect the exercise intensity in controlled skilled games. Grounded in our knowledge, no studies have assessed cognitive flexibility and selective attention. Therefore, the aim of this study is to assess the effects of VR usage, which was hypothesized to deliver additional benefits to a traditional exercise protocol with respect to cognitive flexibility and selective attention.

\section{Materials and Methods}

Thirty healthy males (mean \pm SD, age: $22.8 \pm 2.3$ years, height: $1.73 \pm 0.8 \mathrm{~m}$, mass: $67.3 \pm 8.0 \mathrm{~kg}$ ) volunteered to participate in the study. Participants were familiarized with the procedures and were randomly assigned to one of two groups. Both groups had the same exercise protocol: (1) an experimental group (GE, $n=15)$ that performed an exercise protocol with a virtual reality game, and (2) a controlled group that performed the exercise protocol without the virtual reality (CON, $n=15)$. Individuals were excluded (1) if known metabolic, respiratory, or cardiovascular conditions were present or (2) if they were unable to perform moderate to vigorous exercise.

\subsection{Experimental Approach}

The participants were assessed and required to refrain from exercise, caffeine, or alcohol for $24 \mathrm{~h}$ prior to testing. Informed consent agreements were signed by participants, who were instructed on the purpose and risks of the study. The study was conducted according to the Declaration of Helsinki statement and approved by a local ethics committee. 
Participants arrived at the laboratory and a research assistant, blinded to the participants' groups, explained the experimental procedure. After completing a demographic questionnaire, each participant sat comfortably in front of a laptop in a semi-dark room and remained seated for at least $10 \mathrm{~min}$. Subsequently, after a practice block of 10 trials to ensure that the participants understood the task rules, the participants completed the WCST and the Stroop test. All protocols were performed at the same time of the day ( $\sim 9-11 \mathrm{AM})$ and under similar environmental conditions $\left(22^{\circ} \mathrm{C}\right.$ and $60 \%$ humidity, approximately). Next, a standardized $8 \mathrm{~min}$ warm-up, consisting of $3 \mathrm{~min}$ of joint mobilization exercises and $5 \mathrm{~min}$ of an electronically braked cycle ergometer (Ergoselect 200, Ergoline, Germany) at $60 \mathrm{rpm}$, was performed. After the warm-up, participants immediately started the exercise protocol.

Both groups performed a $5 \mathrm{~min}$ warm-up on a cicloergometer and then exercised at a moderate intensity (60-75\% of the maximum heart rate-HRmax) in between 13 and 15 on the Borg scale for $30 \mathrm{~min}$. While performing the exercise protocol, participants in GE wore VR glasses and were engaged in playing the game of Moto VR continuously during the $30 \mathrm{~min}$ period. After the protocol, $5 \mathrm{~min}$ cool down at a self-selected speed was carried out. During the training, the participants were verbally encouraged to maintain the intensity within the established perceived exertion (rather than attain maximum workload), which was continuously monitored by a trained instructor holding a degree in sport science. Contrastingly, the CON participants performed the same exercise protocol but without the VR glasses. The WCST and the Stroop test were assessed again as soon as exercise ceased under the same conditions (Figure 1).

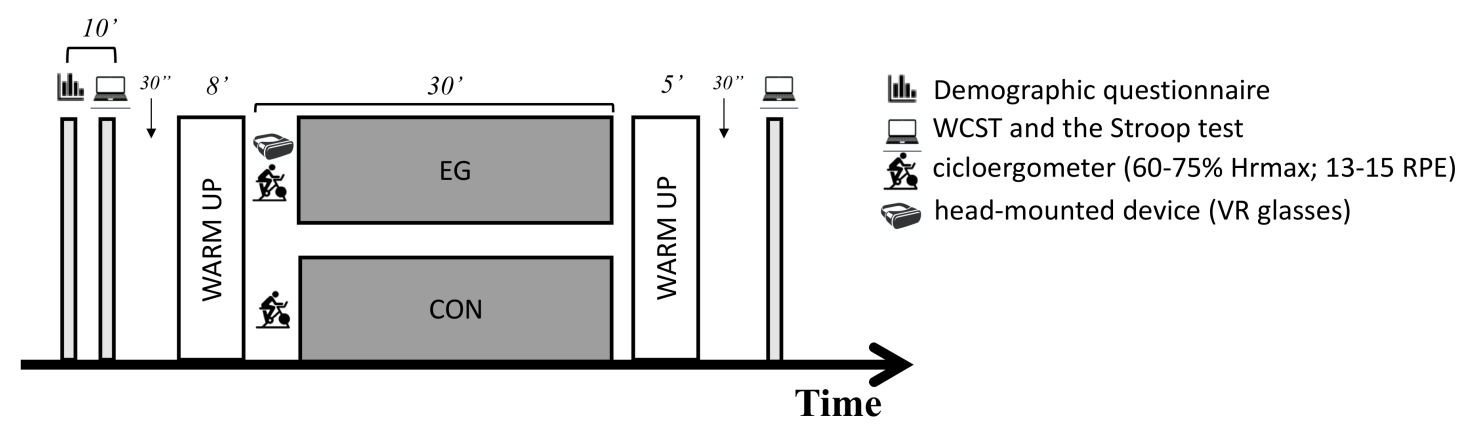

Figure 1. Schematic representation of the study design. EG: exercise group; CON: control group; WCST: Wisconsin Card Sorting Task.

\subsection{Exercise Protocol}

Participants from both groups exercised on the cycle ergometer (Ergoselect 200, Ergoline, Germany) at a moderate intensity (60-75\% HRmax) and between 13 and 15 on the Borg scale for $30 \mathrm{~min}$. After the protocol, 5 min cool down at a self-selected speed was allowed. HRmax was determined as follows: 209.3-0.72*age [42]. It was controlled during the trial using a heart rate monitor (Polar $囚 R S 800 \mathrm{cx}$, Kempele, Finland). The rationale of using this protocol was based on a previous study which used the same protocol to assess the influence of acute exercise on memory [43].

\subsection{Virtual Reality}

Immersive VR through a head-mounted device (Samsung Gear VR) and a Samsung Galaxy S7 using an interactive video game (Moto VR on Steam) was simultaneously employed by GE participants. MotoVR is a game in which participants simulate driving a motorcycle and play in a race against time. The motorcycle body could be tilted with the head using the head-mounted device, and shifting the body (e.g., forward or backward) affected the center of gravity of the motorcycle. This game was selected since it allowed users to automatically continue with the race or start a new one once finished, 
without wasting time. Moreover, these types of games, in which players play in the global view by focusing on visual information, were identified to improve attention (e.g., sustained and divided attention), working memory, and motivation [31,44,45].

\subsection{Outcomes}

The International Physical Activity Questionnaire (IPAQ) long form assesses physical activity intensity levels and differentiates between usual sitting time on a weekday and on a weekend day. Outcome measures from the IPAQ were (a) total physical activity expressed as minutes per day and minutes reported in (b) vigorous-intensity, (c) moderate-intensity activity, and (d) walking time.

\subsection{Wisconsin Card Sorting Task (WCST)}

A 128-card computerized version of the Wisconsin Card Sorting Task (WCST) [46] was used to evaluate subjects' cognitive flexibility. The WCST entails matching stimulus cards with one of four category cards combining the color, shape, and number by pressing one of the four number keys (1-4) on the computer keyboard. Two types of errors are possible (EC): (1) perseveration errors (PEC), in which the participant makes a response applying an old rule, and (2) non-perseverative errors (NPE), which refer to selecting an incorrect card once a sorting rule has been learned.

\subsection{Stroop Test}

The Stroop test was used to assess the ability to inhibit cognitive interference [47], which is the ability to respond to certain environmental stimuli while ignoring others (related to selective attention). The test consisted of a computerized presentation with names of four colors (yellow, blue, green, and red), written in capital letters. Each word appears six times and the same word never appears two consecutive times throughout the test. The subject is instructed to read each word as quickly as possible and select the color in which the word is written while ignoring the meaning of the written word. The number of congruent (C) and incongruent (IC) conditions were measured.

\subsection{Statistical Analyses}

Statistical analysis was performed using JAMOVI software (version 0.9, The Jamovi Project-2019). A two-way mixed repeated measures ANOVA was used with time as within-subjects factor and group as between-subjects factor. Tukey's post-hoc tests were conducted to examine pairwise comparisons among groups. The significance level was set at $p<0.05$. Simple effects in time were also tested using T-paired sample test with Student's T test in the case of normal distribution (assessed via Shapiro Wilk test) or Wilcoxon test in the case of non-parametric data. The magnitude of effects was calculated using partial eta-squared $\left(\eta^{2} p\right.$ ) as follows: $<0.01$ (trivial), 0.01-0.06 (small), 0.06-0.15 (medium), and $>0.15$ (large effects).

\section{Results}

\subsection{Wisconsin Card Sorting Task (WCST)}

As reported in Table 1, there was a significant interaction effect between time and condition for Wisconsin_PEC $\left(\mathrm{F}_{1,30}=4.59, p=0.041, \eta_{\mathrm{p}}^{2}=0.141\right.$-small $)$. There was a significant time effect for WCST in both groups (Table 2). 
Table 1. WCST and Stroop test changes as a result of $30 \mathrm{~min}$ exercise protocol with or without superimposed VR.

\begin{tabular}{|c|c|c|c|c|c|c|c|c|}
\hline & \multicolumn{2}{|c|}{ Pre } & \multicolumn{2}{|c|}{ Post } & \multirow[b]{2}{*}{$p^{a}$} & \multirow[b]{2}{*}{ F } & \multirow[b]{2}{*}{$p^{\mathrm{b}}$} & \multirow[b]{2}{*}{$\eta^{2} p$} \\
\hline & GE & CON & GE & $\mathrm{CON}$ & & & & \\
\hline WCST_EC & $\begin{array}{c}20.1 \\
(9.48)\end{array}$ & $\begin{array}{c}14.9 \\
(6.64)\end{array}$ & $\begin{array}{c}13.3 \\
(7.47)\end{array}$ & $\begin{array}{c}9.27 \\
(3.33)\end{array}$ & 0.420 & 0.215 & 0.647 & 0.008 \\
\hline WCST_PEC & $\begin{array}{c}12.5 \\
(5.50)\end{array}$ & $\begin{array}{c}9.60 \\
(3.78)\end{array}$ & $\begin{array}{c}8.67 \\
(3.31)\end{array}$ & $\begin{array}{c}6.47 \\
(1.73)\end{array}$ & 0.402 & 4.590 & $0.041 *$ & 0.141 \\
\hline WCST_NPEC & $\begin{array}{c}7.60 \\
(5.28)\end{array}$ & $\begin{array}{c}5.27 \\
(3.92)\end{array}$ & $\begin{array}{c}4.60 \\
(4.69)\end{array}$ & $\begin{array}{c}2.80 \\
(2.04)\end{array}$ & 0.640 & 0.09 & 0.761 & 0.003 \\
\hline Stroop_C & $\begin{array}{l}1022 \\
(241)\end{array}$ & $986(201)$ & 839 (170) & 887 (179) & 0.913 & 1.40 & 0.247 & 0.048 \\
\hline Stroop_IC & $\begin{array}{l}1124 \\
(157)\end{array}$ & $\begin{array}{l}1104 \\
(225)\end{array}$ & 947 (149) & 951 (163) & 0.989 & 0.352 & 0.558 & 0.012 \\
\hline
\end{tabular}

All data are reported as mean (SD). WCST: Wisconsin Card Sorting Task; EC: total number of errors; PEC: perseverative errors; NPE: non-perseverative errors; symbols represent significant differences at $p<0.05$. $p^{\text {a }}=$ inter-group differences after treatment using repeated measures ANOVA followed by Tukey's post-hoc; $p^{b}=$ between-groups differences.

Table 2. Intra group differences in WCST and Stroop as a response to a $30 \mathrm{~min}$ exercise protocol with or without superimposed VR.

\begin{tabular}{|c|c|c|c|c|c|c|c|c|}
\hline & \multicolumn{4}{|c|}{ GE } & \multicolumn{4}{|c|}{$\mathrm{CON}$} \\
\hline Wisconsin_EC & $0.006^{*}$ & 6.80 & 2.29 & 11.31 & $0.002 *$ & 5.60 & 2.36 & 8.84 \\
\hline Wisconsin_NPEC & 0.047 * & 3.00 & 0.040 & 5.96 & $0.035 *$ & 2.47 & 0.20 & 4.73 \\
\hline Stroop_C & $0.002 *$ & 183.07 & 76.32 & 289.81 & 0.071 & 99.00 & -97.10 & 207.71 \\
\hline Stroop_IC & $<0.001 *$ & 176.87 & 134.31 & 219.42 & $<0.001^{*}$ & 152.73 & 76.57 & 228.90 \\
\hline
\end{tabular}

WCST: Wisconsin Card Sorting Task; EC: total number of errors; PEC: perseverative errors; NPE: non-perseverative errors; symbols represent significant differences at $p<0.05 .^{*}=$ between-groups differences.

\subsection{Stroop Test}

Non-significant interaction effects between time and condition for Stroop_C $\left(\mathrm{F}_{1,30}=1.40, p=0.247\right.$, $\eta^{2} \mathrm{p}=0.048$-small $)$ and Stroop_IC $\left(\mathrm{F}_{1,30}=0.35, p=0.558, \eta^{2} \mathrm{p}=0.012\right.$-small $)$ were observed. However, while there was a significant time effect for all Stroop outcomes in GE (Table 2), non-significant intra-group changes were observed in CON for Stroop_C $(p=0.071)$.

\section{Discussion}

Few studies have investigated the implementation of VR in healthy young individuals. Moreover, to the best of our knowledge, this is the first study that has assessed cognitive flexibility and selective attention using this technology. Therefore, the aim of this study was to investigate the effects of VR usage which would deliver additional benefits to a traditional exercise protocol with respect to assessing cognitive flexibility and selective attention. The main results of the present study were as follows: (1) there was a significant interaction effect between time and condition for Wisconsin_PEC, (2) there was a significant time effect for WCST in both groups, (3) there was a significant time effect for all Stroop outcomes in GE; however, non-significant intra-group changes were observed in CON for Stroop_C.

In comparing our results to the WCST, the previous studies confirmed that exercise may be helpful in maintaining executive functions and behavioral performance levels [48]. In addition, the study confirmed that moderate exercise improves brain efficiency for executive functions in young adults. In the current study, a significant time effect for WCST in both groups was observed which was in agreement with previous studies using moderate-intensity protocols $[49,50]$. 
Further studies confirmed that a single session of low-volume, supramaximal interval exercise significantly increases executive function [51]. In addition, an acute bout of exercise (cycling at moderate intensity) can improve performance on an executive function task [52,53]. The reduction in non-perseverative errors on the WCST may reflect improved attention, inhibition, and overall working memory [54]. Meanwhile, a previous study [55] suggested that transient hypofrontality occurs during high-intensity exercise, but not during low- and moderate-intensity exercises. Nevertheless, a certain level of intensity seems to be needed in order to release dopamine and influence the activation of different cortex areas [56,57].

The Contingent Continuous Performance Task and WCST tests were used in a previous study [58] as measures of executive control. Following the ventilatory threshold, executive control performance remained poor, possibly owing to the additional amount of time which the brain needs in order to return to homeostasis following intense exercise. According to Chang et al. [59], tentative explanations for the exercise effect postulate that exercise allocates attention resources, influences the dorsolateral prefrontal cortex, and is implicated in exercise-induced dopamine release. Widely in use for more than half a century after the initial presentation of the WCST, there are limitations to classical tasks with VR which must be overcome [60]. Nonetheless, WCST in VR has been comprehensively used in neuropsychology clinical research [61] and in physically unhealthy older adults [24].

There are no previous studies with exercise to the knowledge of the researchers of this study. Therefore, the results are compared with other topics similar to current research. Once Biró et al. [62] developed a two-choice rule-switch task with mice, they concluded that the animals learnt to discriminate between the visual cues and successfully switched their strategies according to the related rules. The findings support the role of prefrontal networks in mice for cognitive flexibility.

In a previous study, Delahaye et al. [63] used VR technology to induce stress and to test three main cognitive functions for decision-making in stressful situations. The results indicated that if someone perceived the virtual Trier Social Stress Test (TSST) as unexpected, as an indicator of a mild stress response, their cognitive flexibility was improved; meanwhile, the authors of [64] examined the VR more closely to approximately reflect real-life settings, distractions, and common interchanges using WCST and Look for a Match (LFAM). The results demonstrated that the participants found LFAM to be more enjoyable and interesting, whereas they found the WCST to be easier.

Maintaining a certain level of physical activity has beneficial effects on the body itself but also, surprisingly, on cognition [65]. Despite new developments, a large portion of VR's potential is still unexplored; therefore, real experiences in a flexible context that combine relevant cultural, physical, and cognitive aspects are necessary [66]. To date, cognitive flexibility has been measured only using neuropsychological tasks; therefore, the VR task was developed to evaluate cognitive flexibility [67].

A previous study [68] investigated immersive VR as a novel technique to test the executive function of healthy younger and older adults. The conclusion drawn from the study indicated that immersive VR measures were found to be stronger contributors than existing traditional neuropsychological tasks in predicting age-related cognitive decline. Accordingly, the physiological explanation of VR in improvements of cognitive reality is severely limited.

To the best of our knowledge, this is the first study conducted with healthy adults in this field; hence, there is no point of reference with the same population as to the current study. Nonetheless, the authors of [69] studied older adults at risk for mild cognitive impairments, the authors of [70] studied patients with brain injury, and the authors of [71] studied cardiac rehabilitation patients—all utilized the Stroop test. Performance in VR was present in all three studies. Utilizing the Stroop test in all three studies found that the implementation of immersive VR interventions is effective in improving specific executive functions and information processing. These findings are in line with those collected in our study while employing the Stroop test.

Utilizing VR can have added effects when compared with traditional exercise. The research confirms that VR-enhanced aerobic exercise may prove to be an effective method for improving cognitive function and increasing confidence to navigate real-world scenarios among individuals at 
risk of cognitive impairment [72]. In an additional similar study, over $50 \%$ of participants stated that they preferred the VR condition compared to the traditional workout and claimed that it improved their focus [73]. A review of the literature examining the effects of VR suggested that VR exercise has the potential to exert a positive impact on individuals' physiological, psychological, and rehabilitative outcomes compared with traditional exercise [74].

The main limitations of the study were (1) the sample characteristics of only young healthy males and (2) the size. The participants were 30 healthy adults with no known pre-existing conditions. A larger sample, perhaps including healthy and unhealthy populations, is suggested for future studies. In addition, based on our knowledge, this was the first study to investigate the effects of VR usage in terms of delivering additional benefits to a traditional exercise protocol with respect to assessing cognitive flexibility and selective attention.

\section{Conclusions}

Overall, the current investigation offers a proof of concept that VR intervention can affect the use of VR to provide additional benefits to a traditional exercise protocol with respect to cognitive flexibility and selective attention in healthy adults. The VR provides an interactive and visually stimulating approach. With evidence, this alternate specialized intervention platform could provide training for those who may not have motivational domain. The quality, quantity, and sample size of the existing study are far from ideal. Therefore, more studies are needed to confirm the observed positive effects.

Author Contributions: Conceptualization, investigation, B.S.; writing-original draft preparation, E.A.; supervision, M.B.-F.; review and editing, R.T. All authors have read and agreed to the published version of the manuscript.

Funding: This research received no external funding.

Conflicts of Interest: The authors declare no personal circumstances or interests which may be perceived as inappropriately influencing the representation or interpretation of the reported research results. Therefore, the authors declare no conflict of interest.

\section{References}

1. Fiuza-Luces, C.; Garatachea, N.; Berger, N.A.; Lucia, A. Exercise is the real polypill. Physiology 2013, 28, 330-358. [CrossRef] [PubMed]

2. Colberg, S.R.; Sigal, R.J.; Yardley, J.E.; Riddell, M.C.; Dunstan, D.W.; Dempsey, P.C.; Horton, E.S.; Castorino, K.; Tate, D.F. Physical activity/exercise and diabetes: A position statement of the American Diabetes Association. Diabetes Care 2016, 39, 2065-2079. [CrossRef] [PubMed]

3. Matthews, C.E.; Moore, S.C.; Sampson, J.; Blair, A.; Xiao, Q.; Keadle, S.K.; Hollenbeck, A.; Park, Y. Mortality Benefits for Replacing Sitting Time with Different Physical Activities. Med. Sci. Sports Exerc. 2015, 47, 1833-1840. [CrossRef] [PubMed]

4. Oja, P.; Titze, S.; Kokko, S.; Kujala, U.M.; Heinonen, A.; Kelly, P.; Koski, P.; Foster, C. Health benefits of different sport disciplines for adults: Systematic review of observational and intervention studies with meta-analysis. Br. J. Sports Med. 2015, 49, 434-440. [CrossRef]

5. Pedersen, B.K.; Saltin, B. Exercise as medicine-Evidence for prescribing exercise as therapy in 26 different chronic diseases. Scand. J. Med. Sci. Sport. 2015, 25 (Suppl. 3), 1-72. [CrossRef]

6. Pedersen, B.K.; Saltin, B. Evidence for prescribing exercise as therapy in chronic disease. Scand. J. Med. Sci. Sport. 2006, 16, 3-63. [CrossRef]

7. Matsuda, P.N.; Shumway-Cook, A.; Ciol, M.A. The effects of a home-based exercise program on physical function in frail older adults. J. Geriatr. Phys. Ther. 2010, 33, 78-84.

8. Jerdan, S.W.; Grindle, M.; Van Woerden, H.C.; Kamel Boulos, M.N. Head-mounted virtual reality and mental health: Critical review of current research. JMIR Serious Games. 2018, 6, e14. [CrossRef]

9. Mihelj, M.; Novak, D.; Beguš, S. Virtual Reality Technology and Applications. Intell. Syst. Control. Autom. Sci. Eng. 2014. [CrossRef] 
10. Zhang, T.; Booth, R.; Jean-Louis, R.; Chan, R.; Yeung, A.; Gratzer, D.; Strudwick, G. A Primer on Usability Assessment Approaches for Health-Related Applications of Virtual Reality. JMIR Serious Games 2020, 8, e18153. [CrossRef]

11. Neumann, D.L.; Moffitt, R.L.; Thomas, P.R.; Loveday, K.; Watling, D.P.; Lombard, C.L.; Antonova, S.; Tremeer, M.A. A systematic review of the application of interactive virtual reality to sport. Virtual Real. 2018, 22, 183-198. [CrossRef]

12. Rose, T.; Nam, C.S.; Chen, K.B. Immersion of virtual reality for rehabilitation-Review. Appl. Ergon. 2018, 69, 153-161. [CrossRef] [PubMed]

13. Finkelstein, S.; Nickel, A.; Lipps, Z.; Barnes, T.; Wartell, Z.; Suma, E.A. Astrojumper: Motivating exercise with an immersive virtual reality exergame. Presence Teleoper. Virtual Environ. 2011, 20, 78-92. [CrossRef]

14. Anderson-Hanley, C.; Snyder, A.L.; Nimon, J.P.; Arciero, P.J. Social facilitation in virtual reality-enhanced exercise: Competitiveness moderates exercise effort of older adults. Clin. Interv. Aging 2011, 6, $275-280$. [CrossRef] [PubMed]

15. Lau, K.W.; Lee, P.Y. The use of virtual reality for creating unusual environmental stimulation to motivate students to explore creative ideas. Interact. Learn. Environ. 2015, 23, 3-18. [CrossRef]

16. Freeman, D.; Reeve, S.; Robinson, A.; Ehlers, A.; Clark, D.; Spanlang, B.; Slater, M. Virtual reality in the assessment, understanding, and treatment of mental health disorders. Psychol. Med. 2017, 47, 2393-2400. [CrossRef]

17. Martin Ginis, K.A.; Jörgensen, S.; Stapleton, J. Exercise and sport for persons with spinal cord injury. $P M R$ 2012, 4, 894-900. [CrossRef]

18. Mohr, D.C.; Burns, M.N.; Schueller, S.M.; Clarke, G.; Klinkman, M. Behavioral Intervention Technologies: Evidence review and recommendations for future research in mental health. Gen. Hosp. Psychiatry 2013, 35, 332-338. [CrossRef]

19. Valmaggia, L.R.; Latif, L.; Kempton, M.J.; Rus-Calafell, M. Virtual reality in the psychological treatment for mental health problems: An systematic review of recent evidence. Psychiatry Res. 2016, 236, 189-195. [CrossRef]

20. Cuthbert, R.; Turkay, S.; Brown, R. The effects of customisation on player experiences and motivation in a virtual reality game. In OZCHI'19, Proceedings of the 31st Australian Conference on Human-Computer-Interaction, Fremantle, Australia, 3-5 December 2019; ACM International Conference Proceeding Series; Association for Computing Machinery: New York, NY, USA, 2019.

21. Lin, I.-H.; Tsai, H.-T.; Wang, C.-Y.; Hsu, C.-Y.; Liou, T.-H.; Lin, Y.-N. Effectiveness and Superiority of Rehabilitative Treatments in Enhancing Motor Recovery within 6 Months Poststroke: A Systemic Review. Arch. Phys. Med. Rehabil. 2019, 100, 366-378. [CrossRef]

22. Lee, H.S.; Lim, J.H.; Jeon, B.H.; Song, C.S. Non-immersive Virtual Reality Rehabilitation Applied to a Task-oriented Approach for Stroke Patients: A Randomized Controlled Trial. Restor. Neurol. Neurosci. 2020, 38, 165-172. [CrossRef] [PubMed]

23. Lin, R.C.; Chiang, S.L.; Heitkemper, M.M.L.; Weng, S.M.; Lin, C.F.; Yang, F.C.; Lin, C.H. Effectiveness of Early Rehabilitation Combined With Virtual Reality Training on Muscle Strength, Mood State, and Functional Status in Patients With Acute Stroke: A Randomized Controlled Trial. Worldviews Evid. Based Nurs. 2020, 17, 158-167. [CrossRef] [PubMed]

24. Oliveira, J.; Gamito, P.; Lopes, B.; Silva, A.R.; Galhordas, J.; Pereira, E.; Ramos, E.; Silva, A.P.; Jorge, Á.; Fantasia, A. Computerized cognitive training using virtual reality on everyday life activities for patients recovering from stroke. Disabil. Rehabil. Assist. Technol. 2020. [CrossRef] [PubMed]

25. Howard, M.C. A meta-analysis and systematic literature review of virtual reality rehabilitation programs. Comput. Human Behav. 2017, 70, 317-327. [CrossRef]

26. Mosadeghi, S.; Reid, M.W.; Martinez, B.; Rosen, B.T.; Spiegel, B.M.R. Feasibility of an Immersive Virtual Reality Intervention for Hospitalized Patients: An Observational Cohort Study. JMIR Ment. Health 2016, 3, e28. [CrossRef]

27. Hsieh, K.L.; Mirelman, A.; Shema-Shiratzky, S.; Galperin, I.; Regev, K.; Shen, S.; Schmitz-Hübsch, T.; Karni, A.; Paul, F.; Devos, H.; et al. A multi-modal virtual reality treadmill intervention for enhancing mobility and cognitive function in people with multiple sclerosis: Protocol for a randomized controlled trial. Contemp. Clin. Trials 2020. [CrossRef] 
28. Huang, K.T. Exergaming Executive Functions: An Immersive Virtual Reality-Based Cognitive Training for Adults Aged 50 and Older. Cyberpsychology Behav. Soc. Netw. 2020, 23, 143-149. [CrossRef]

29. Man, D.W.K. Virtual reality-based cognitive training for drug abusers: A randomised controlled trial. Neuropsychol. Rehabil. 2020, 30, 315-332. [CrossRef]

30. Côté, S.; Bouchard, S. Cognitive mechanisms underlying virtual reality exposure. Cyberpsychol. Behav. 2009, 12, 121-129. [CrossRef]

31. Choi, E.; Shin, S.-H.; Ryu, J.-K.; Jung, K.-I.; Kim, S.-Y.; Park, M.-H. Commercial video games and cognitive functions: Video game genres and modulating factors of cognitive enhancement. Behav. Brain Funct. 2020, 16, 2. [CrossRef]

32. Vogel, J.J.; Vogel, D.S.; Cannon-Bowers, J.; Bowers, G.A.; Muse, K.; Wright, M. Computer gaming and interactive simulations for learning: A meta-analysis. J. Educ. Comput. Res. 2006, 34, 229-243. [CrossRef]

33. Moreau, D.; Morrison, A.B.; Conway, A.R.A. An ecological approach to cognitive enhancement: Complex motor training. Acta Psychol. (Amst.) 2015, 157, 44-55. [CrossRef] [PubMed]

34. Mahon, B.Z.; Caramazza, A. A critical look at the embodied cognition hypothesis and a new proposal for grounding conceptual content. J. Physiol. Paris 2008, 102, 59-70. [CrossRef] [PubMed]

35. Tomporowski, P.D.; Pesce, C. Exercise, sports, and performance arts benefit cognition via a common process. Psychol. Bull. 2019, 145, 929-951. [CrossRef] [PubMed]

36. Shin, D.H. The role of affordance in the experience of virtual reality learning: Technological and affective affordances in virtual reality. Telemat. Inform. 2017, 34, 1826-1836. [CrossRef]

37. Huang, Y.C.; Backman, S.J.; Backman, K.F.; McGuire, F.A.; Moore, D.W. An investigation of motivation and experience in virtual learning environments: A self-determination theory. Educ. Inf. Technol. 2019, 24, 591-611. [CrossRef]

38. Sik Lanyi, C.; Szucs, V. Motivating rehabilitation through competitive Gaming. In Modern Stroke Rehabilitation through e-Health-Based Entertainment; Springer: Berlin/Heidelberg, Germany, 2015; ISBN 9783319212920.

39. Shaw, A.; Buckley, J.; Corballis, P.; Lutteroth, C.; Wuensche, B. Exploring the Possibility of Virtual Reality Exergaming as a Cognitive Screening System. In Proceedings of the 53rd Hawaii International Conference on System Sciences, Maui, HI, USA, 7-10 January 2020.

40. Murray, E.G.; Neumann, D.L.; Moffitt, R.L.; Thomas, P.R. The effects of the presence of others during a rowing exercise in a virtual reality environment. Psychol. Sport Exerc. 2016, 22, 328-336. [CrossRef]

41. O'Donovan, C.; Hussey, J. Active video games as a form of exercise and the effect of gaming experience: A preliminary study in healthy young adults. Physiother. (U. K.) 2012, 98, 205-210. [CrossRef]

42. Arena, R.; Myers, J.; Kaminsky, L.A. Revisiting age-predicted maximal heart rate: Can it be used as a valid measure of effort? Am Heart J. 2016, 173, 49-56. [CrossRef]

43. Labban, J.D.; Etnier, J.L. Effects of acute exercise on long-term memory. Res. Q. Exerc. Sport 2011, 82, 712-721. [CrossRef]

44. Huang, V.; Young, M.; Fiocco, A.J. The Association between Video Game Play and Cognitive Function: Does Gaming Platform Matter? Cyberpsychology Behav. Soc. Netw. 2017, 20, 689-694. [CrossRef] [PubMed]

45. Baniqued, P.L.; Kranz, M.B.; Voss, M.W.; Lee, H.; Cosman, J.D.; Severson, J.; Kramer, A.F. Cognitive training with casual video games: Points to consider. Front. Psychol. 2014, 4, 1010. [CrossRef] [PubMed]

46. Heaton, R.K.; Chelune, G.J.; Talley, J.L.; Kay, G.G.; Curtiss, G. Wisconsin Card Sorting Test Manual: Revised and Expanded; Psychological Assessment Resources: Odessa, FL, USA, 1993.

47. Scarpina, F.; Tagini, S. The stroop color and word test. Front. Psychol. 2017, 8, 557. [CrossRef] [PubMed]

48. Song, H.; Kim, J.G.; Jang, K.E.; Cha, H.; Kwon, S.; Jeong, H.; Chang, Y. Moderate Exercise Improves Brain Efficiency for Executive Functions in Young Adults. J. Med. Imaging Health Inform. 2019, 10, 782-785. [CrossRef]

49. Bellack, A.S.; Blanchard, J.J.; Murphy, P.; Podell, K. Generalization effects of training on the Wisconsin Card Sorting Test for schizophrenia patients. Schizophr. Res. 1996, 19, 189-194. [CrossRef]

50. Kulisevsky, J.; Avila, A.; Barbanoj, M.; Antonijoan, R.; Berthier, M.L.; Gironell, A. Acute effects of levodopa on neuropsychological performance in stable and fluctuating Parkinson's disease patients at different levodopa plasma levels. Brain 1996, 119, 2121-2132. [CrossRef]

51. Slusher, A.L.; Patterson, V.T.; Schwartz, C.S.; Acevedo, E.O. Impact of high intensity interval exercise on executive function and brain derived neurotrophic factor in healthy college aged males. Physiol. Behav. 2018, 191, 116-122. [CrossRef] 
52. Pontifex, M.B.; Hillman, C.; McAuley, E. The acute effects of yoga on executive function neha gothe1. J. Phys. Act. Health 2013, 10, 488-495.

53. Mehren, A.; Özyurt, J.; Lam, A.P.; Brandes, M.; Müller, H.H.O.; Thiel, C.M.; Philipsen, A. Acute effects of aerobic exercise on executive function and attention in adult patients with ADHD. Front. Psychiatry 2019, 10, 132. [CrossRef]

54. Subramaniapillai, M.; Tremblay, L.; Grassmann, V.; Remington, G.; Faulkner, G. The effect of an acute bout of exercise on executive function among individuals with schizophrenia. Psychiatry Res. 2016, 246, 637-643. [CrossRef]

55. Wang, Y.; Du, R.; Yu, T. Systematical method for polyacrylamide and residual acrylamide detection in cosmetic surgery products and example application. Sci. Justice 2013, 53, 350-357. [CrossRef] [PubMed]

56. Inoue, T.; Tsuchiya, K.; Koyama, T. Regional changes in dopamine and serotonin activation with various intensity of physical and psychological stress in the rat brain. Pharmacol. Biochem. Behav. 1994, 49, 911-920. [CrossRef]

57. Silveira, R.; Prado, R.C.R.; Brietzke, C.; Coelho-Júnior, H.J.; Santos, T.M.; Pires, F.O.; Asano, R.Y. Prefrontal cortex asymmetry and psychological responses to exercise: A systematic review. Physiol. Behav. 2019, 208, 112580. [CrossRef] [PubMed]

58. Del Giorno, J.M.; Hall, E.E.; O’Leary, K.C.; Bixby, W.R.; Miller, P.C. Cognitive function during acute exercise: A test of the transient hypofrontality theory. J. Sport Exerc. Psychol. 2010, 32, 312-323. [CrossRef] [PubMed]

59. Chang, Y.K.; Liu, S.; Yu, H.H.; Lee, Y.H. Effect of acute exercise on executive function in children with attention deficit hyperactivity disorder. Arch. Clin. Neuropsychol. 2012, 27, 225-237. [CrossRef] [PubMed]

60. Krohn, S.; Tromp, J.; Quinque, E.M.; Belger, J.; Klotzsche, F.; Rekers, S.; Chojecki, P.; De Mooij, J.; Akbal, M.; McCall, C.; et al. Multidimensional Evaluation of Virtual Reality Paradigms in Clinical Neuropsychology: Application of the VR-Check Framework. J. Med. Internet Res. 2020, 22, e1672. [CrossRef] [PubMed]

61. Castelnuovo, G.; Lo Priore, C.; Liccione, D.; Cioffi, G. Virtual reality based tools for the rehabilitation of cognitive and executive functions: The V-STORE. PsychNology J. 2003, 1, 310-325.

62. Biró, S.; Lasztóczi, B.; Klausberger, T. A visual two-choice rule-switch task for head-fixed mice. Front. Behav. Neurosci. 2019. [CrossRef]

63. Delahaye, M.; Lemoine, P.; Cartwright, S.; Deuring, G.; Beck, J.; Pflueger, M.; Graf, M.; Hachtel, H. Learning aptitude, spatial orientation and cognitive flexibility tested in a virtual labyrinth after virtual stress induction. BMC Psychol. 2015, 3, 22. [CrossRef]

64. Elkind, J.S.; Rubin, E.; Rosenthal, S.; Skoff, B.; Prather, P. A simulated reality scenario compared with the computerized Wisconsin Card Sorting Test: An analysis of preliminary results. Cyberpsychology Behav. 2001, 4, 489-496. [CrossRef]

65. Burin, D.; Yamaya, N.; Ogitsu, R.; Kawashima, R. Virtual training leads to real acute physical, cognitive, and neural benefits on healthy adults: Study protocol for a randomized controlled trial. Trials 2019, 20, 1-12. [CrossRef] [PubMed]

66. De Carvalho, M.R.; Freire, R.C.; Nardi, A.E. Virtual reality as a mechanism for exposure therapy. World J. Biol. Psychiatry 2010, 11, 220-230. [CrossRef] [PubMed]

67. Han, K.; Young Kim, I.; Kim, J.J. Assessment of cognitive flexibility in real life using virtual reality: A comparison of healthy individuals and schizophrenia patients. Comput. Biol. Med. 2012, 42, 841-847. [CrossRef] [PubMed]

68. Davison, S.M.C.; Deeprose, C.; Terbeck, S. A comparison of immersive virtual reality with traditional neuropsychological measures in the assessment of executive functions. Acta Neuropsychiatr. 2018, 30, 79-89. [CrossRef]

69. Anderson-Hanley, C.; Barcelos, N.M.; Zimmerman, E.A.; Gillen, R.W.; Dunnam, M.; Cohen, B.D.; Yerokhin, V.; Miller, K.E.; Hayes, D.J.; Arciero, P.J.; et al. The Aerobic and Cognitive Exercise Study (ACES) for community-dwelling older adults with or at-risk for mild cognitive impairment (MCI): Neuropsychological, neurobiological and neuroimaging outcomes of a randomized clinical trial. Front. Aging Neurosci. 2018, 10, 76. [CrossRef]

70. Dahdah, M.N.; Bennett, M.; Prajapati, P.; Parsons, T.D.; Sullivan, E.; Driver, S. Application of virtual environments in a multi-disciplinary day neurorehabilitation program to improve executive functioning using the Stroop task. NeuroRehabilitation 2017, 41, 721-734. [CrossRef] 
71. Vieira, Á.; Melo, C.; Machado, J.; Gabriel, J. Virtual reality exercise on a home-based phase III cardiac rehabilitation program, effect on executive function, quality of life and depression, anxiety and stress: A randomized controlled trial. Disabil. Rehabil. Assist. Technol. 2018, 13, 112-123. [CrossRef]

72. Palac, D.; Bullard, T.; Cohen, J.D.; Nguyen, L.T.; Mudar, R.A.; Mullen, S.P. Effects of traditional vs. iPad-enhanced aerobic exercise on wayfinding efficacy and cognition: A pilot randomized controlled trial. Int. J. Environ. Res. Public Health 2019, 16, 3495. [CrossRef]

73. McClure, C.; Schofield, D. Running virtual: The effect of virtual reality on exercise. J. Hum. Sport Exerc. 2019. [CrossRef]

74. Qian, J.; McDonough, D.J.; Gao, Z. The effectiveness of virtual reality exercise on individual's physiological, psychological and rehabilitative outcomes: A systematic review. Int. J. Environ. Res. Public Health 2020, 17, 4133. [CrossRef]

Publisher's Note: MDPI stays neutral with regard to jurisdictional claims in published maps and institutional affiliations.

(C) 2020 by the authors. Licensee MDPI, Basel, Switzerland. This article is an open access article distributed under the terms and conditions of the Creative Commons Attribution (CC BY) license (http://creativecommons.org/licenses/by/4.0/). 